\title{
TEORES DE CARBOIDRATOS EM ESTACAS LENHOSAS DE MIRTILEIRO ${ }^{1}$
}

\author{
RÉRINTON JOABÉL PIRES DE OLIVEIRA², VALMOR JOÃO BIANCHI ${ }^{3}$, \\ ROGÉRIO FERREIRA AIRES ${ }^{4}$, ÂNGELA DINIZ CAMPOS ${ }^{5}$
}

RESUMO-O objetivo do trabalho foi avaliar as alterações no teor de carboidratos em estacas lenhosas de mirtileiro das cultivares Delite, Powder Blue e Seleção 19. O trabalho foi dividido em dois experimentos, primeiramente foram analisados os teores de amido e de açúcares solúveis a partir de ramos coletados em quatro épocas (03-06, 04-07, 24-07 e 11-08-2008) e, posteriormente, avaliou-se o teor de carboidratos em estacas coletadas nas mesmas épocas citadas, porém submetidas ao enraizamento e avaliadas em diferentes épocas (03-06, 04-07, 04-08, 03-09 e 03-10; 04-07, 04-08, 03-09, 03-10; 24-07, 04-08, 03-09 e 03-10; 1108, 03-09 e 03-10). Verificou-se que a cultivar Powder Blue tem maior concentração de amido nos ramos que as cultivares Delite e Seleção 19. Estacas lenhosas de mirtileiro com baixos teores de amido, quando submetidas ao enraizamento, apresentam ressíntese de amido. No fim do período de inverno, ocorre aumento na concentração de amido nos ramos lenhosos de mirtileiro. Este aumento ao final do período de inverno está associado à maior taxa de enraizamento.

Termos para indexação: Vaccinium ashei Reade, amido, açúcares solúveis.

\section{CARBOHIDRATES CONTENT IN HARDWOOD CUTTINGS OF BLUEBERRY}

ABSTRACT - The aim at this study was to evaluate the alterations on carbohydrates metabolism of hardwood cuttings of blueberries cv. Delite, Powder Blue and Seleção 19. The starch and soluble sugars concentration were evaluated in blueberry branches at four different times in a first experiment (06/03, 07/04, 07/24 and 08/11/2008) and later the metabolism of carbohydrates were evaluated in harvested hardwood cuttings submitted to rooting conditions $(06 / 03,07 / 04,08 / 04,09 / 03$ and 10/03; 07/04, 08/04, 09/03 and 10/03; $07 / 24,08 / 04,09 / 03$ and 10/03; 08/11,09/03 and 10/03). It was verified that the cv. Powder Blue has higher starch concentration in the branches than Delite and Seleção 19. Hardwood cuttings of blueberry with low percentage of starch, when subjected to rooting, have resynthesis of starch. At the end of the winter, there is an increase in starch in the branches of woody blueberry. A higher amount of starch in the branches during the winter is associated to a higher rate of rooting.

Index terms: Vaccinium ashei Reade; starch; soluble sugar.

\section{INTRODUÇÃO}

As frutíferas de clima temperado, durante o período de outono/inverno, apresentam o fenômeno da dormência, e neste período ocorrem alterações na dinâmica dos carboidratos presentes nos tecidos vegetais (LACOINTE et al., 1993).

No metabolismo da dormência, logo no início, ocorre a conversão dos açúcares em amido, processo que garante o armazenamento de reservas, com a máxima concentração de amido no final do outono, marcado pelo início da queda das folhas (SCHRADER; SAUTER, 2002). Com o início do inverno e das baixas temperaturas, ocorre o aumento da atividade das amilases e fosforilases, que promovem a hidrólise do amido para a formação de açúcares solúveis.

Segundo Gupta e Kaur (2005), os açúcares atuam protegendo os tecidos contra as baixas temperaturas. No entanto, o papel crucial na resistência ao congelamento nas plantas ainda não está claro (KLOTKE et al., 2004). Os açúcares parecem estar envolvidos na tolerância dos tecidos em zero grau, em pelo menos duas maneiras: primeiro, por seu efeito osmótico, diminuem a quantidade de gelo formado no vacúolo; em segundo lugar, por seu efeito metabólico, sendo convertido no protoplasma em

${ }^{1}$ (Trabalho 124-12). Recebido em: 09-04-2012. Aceito para publicação em: 05-06-2012.

${ }^{2}$ MSc - Embrapa Clima Temperado - BR 392 km 78, Cx. Postal 403, CEP 96001-970 - E-mail: rerinton@yahoo.com.br

${ }^{3}$ DSc - Universidade Federal de Pelotas Caixa Postal 354 - CEP 96010-900- E-mail: valmorjb@yahoo.com

${ }^{4}$ DSc - Embrapa Clima Temperado - BR 392 km 78, Cx. Postal 403, CEP 96001-970 - E-mail: aires@ymail.com

${ }^{5}$ DSc - Responsável pelo Laboratório de Fisiologia Vegetal - Embrapa Clima Temperado - BR 392 km 78, Cx. Postal 403, CEP 96001-970 - E-mail: angela.campos@cpact.embrapa.br. 
outros componentes. Se essas mudanças envolvem a conversão de açúcares comuns a poliálcoois, ou se é mais complexa ainda, atualmente não se tem conhecimento sobre esse processo.

A hidrólise do amido tanto pode ocorrer sob baixas temperaturas durante o inverno como também no início da primavera com o aumento progressivo da temperatura, coincidindo com a presença de novas brotações na primavera. Essa nova mobilização do amido, que normalmente ocorre na ausência de baixas temperaturas, é regulada basicamente por outras amilases, como a $\alpha$-amilase e a fosforilase (GUY et al., 2008). Entre estas duas fases de mobilização do amido, pode ocorrer o inverso, ou seja, os açúcares solúveis reconstituírem-se novamente em grânulos de amido, devido ao suprimento de açúcares solúveis superarem a demanda celular para o crescimento e a respiração, em um processo metabólico chamado de ressíntese de amido (SCHRADER; SAUTER, 2002).

$\mathrm{O}$ estudo dessas relações metabólicas que envolvem a interconversão de carboidratos é importante para o entendimento do fluxo e consumo de fotoassimilados e reservas, tanto em plantas inteiras quanto em órgãos destacados, como no caso de estacas lenhosas submetidas ao enraizamento.

Davis e Potter (1981), estudando a fotossíntese e carboidratos correlacionados com a formação de raízes, verificaram que o suprimento de fotoassimilados para a base das estacas é importante para o enraizamento. Os autores associaram 50\% do enraizamento com o suprimento de fotoassimilados, porém não estabeleceram se há influência direta sobre o enraizamento ou indireta sobre outros fatores.

As auxinas constituem um grupo de fitormônios que podem influenciar significativamente o enraizamento e as brotações, pois estão relacionadas com a divisão celular, estimulando a síntese ou desinibindo a ação de enzimas que atuam sobre as microfibrilas da parede celular, promovendo a plasticidade da membrana (TAIZ; ZEIGER, 2009). Estas são sintetizadas principalmente nos meristemas apicais de caules e folhas, e são transportadas basipetamente via transporte polar para a extremidade basal da planta ou órgão da planta (LJUNG et al., 2002). Esse processo é dependente de energia, pela sensibilidade do transporte polar à falta de $\mathrm{O}_{2}$, ocasionando diminuição de sacarose e, consequentemente, gasto de energia (TAIZ; ZEIGER, 2009).

Sendo assim, a capacidade de um caule emitir raízes é função da interação de vários fatores, bem como de substâncias translocáveis produzidas nas folhas e gemas, como auxinas, carboidratos, compostos nitrogenados e outros.

O presente trabalho foi desenvolvido com o objetivo de avaliar as modificações nos teores de carboidratos em estacas lenhosas de três genótipos de mirtileiro, coletadas no período de outono-inverno, submetidas a condições de enraizamento, e a influência dos teores de carboidratos no comportamento das estacas submetidas ao enraizamento.

\section{MATERIAL E MÉTODOS}

O trabalho foi conduzido na Embrapa Clima Temperado, em Pelotas-RS, no período de maio de 2008 a fevereiro de 2009, em casa de vegetação e no Laboratório de Fisiologia Vegetal, situada na altitude de $60 \mathrm{~m}$ e latitude de $31^{\circ} 41^{\prime}$ sul e longitude $52^{\circ} 21$ oeste.

O material vegetal utilizado consistiu em de ramos lenhosos do ano, das cultivares de mirtileiro Powder Blue, Delite e da Seleção 19, obtidas do banco de germoplasma da Embrapa Clima Temperado, coletados em plantas com 16 anos de idade.

Os ramos coletados foram utilizados para as avaliações nos experimentos 1 e 2, conforme as descrições seguintes.

Experimento 1: Variação no teor de carboidratos em ramos de mirtileiro coletados em quatro épocas, durante o período de outono/inverno.

Para isto, foram coletados oito ramos de aproximadamente 1,5 $\mathrm{m}$ de comprimento e $6 \mathrm{~mm}$ de diâmetro, de três plantas-matrizes para cada genótipo, totalizando 24 ramos por genótipo, em quatro épocas: três de junho, quatro de julho, 24 de julho e 11 de agosto de 2008.

Logo após a coleta, foi retirada uma amostra composta por casca e lenho de aproximadamente $100 \mathrm{~g}$, sendo as mesmas acondicionadas em temperatura de -25 a $-30{ }^{\circ} \mathrm{C}$, para, posteriormente, realizar as análises de quantificação dos teores de amido e de açúcares solúveis totais.

$\mathrm{O}$ delineamento experimental utilizado foi o inteiramente casualizado, com três repetições por tratamento, segundo um fatorial $3 \times 4$, constando de três genótipos (Powder Blue, Delite e Seleção 19), em quatro épocas de coleta dos ramos. Após a coleta dos ramos, parte foi utilizada para a confecção das estacas e para as análises bioquímicas.

O material vegetal para as análises de açúcares solúveis totais foi seco em estufa com circulação de ar a $60{ }^{\circ} \mathrm{C}$, e moído em moinho de facas até a obtenção de uma farinha de granulação bem fina. Em seguida, uma amostra de $100 \mathrm{mg}$ de massa seca (MS) foi colocada em tubo de polipropileno de 15 $\mathrm{mL}$ e adicionados $2,5 \mathrm{~mL}$ de álcool a $80 \%$. A mistura foi homogeneizada com a ajuda de um bastão de vidro e, em seguida, centrifugada por 10 minutos na 
velocidade de $1.000 \mathrm{~g}$. Verteu-se o sobrenadante para um balão volumétrico e completou-se o volume de $10 \mathrm{~mL}$ com água. Esse material foi acondicionado em frascos com tampa para, posteriormente, realizar as análises de açúcares solúveis totais, segundo metodologia preconizada por Horwitz (1975), utilizando a antrona como reagente. As leituras de absorbância foram realizadas em espectrofotômetro UV PC Shimadzu em $620 \mathrm{~nm}$, e os resultados foram expressos em mg de glicose $\mathrm{g}^{-1} \mathrm{MS}$.

O precipitado foi utilizado para as análises de amido, a este foram adicionados $2,5 \mathrm{~mL}$ de ácido perclórico a $30 \%(\mathrm{v} / \mathrm{v})$, e submetido à agitação constante por 30 minutos. Em seguida, essa mistura foi centrifugada por 10 minutos em $1.000 \mathrm{~g}$. O sobrenadante foi coletado e transferido para balão volumétrico de $10 \mathrm{~mL}$, e o volume, completado com água. O doseamento de amido foi através da reação com antrona, segundo Horwitz (1975). Para a curva-padrão utilizou-se da glicose. As leituras de absorbância foram realizadas em espectrofotômetro UV PC Shimadzu em $620 \mathrm{~nm}$, e os resultados foram expressos em mg amido $\mathrm{g}^{-1}$ MS.

Experimento 2: Avaliação da influência dos teores de carboidratos das estacas lenhosas de mirtileiro durante o processo de enraizamento, em quatro épocas do período outono/inverno.

Os ramos colhidos em cada época, durante o período de outono/inverno, tiveram suas bases imersas em $2.000 \mathrm{~mL}$ de água por 24 horas, antes da segmentação. As estacas foram de $15 \mathrm{~cm}$ de comprimento cada. Após a segmentação, o terço inferior de cada estaca foi imerso em água destilada por 10 minutos, para evitar o ressecamento da base. As estacas foram plantadas em caixas de poliestireno expandido de 72 células, contendo substrato comercial Plantmax ${ }^{\circledR} \mathrm{HT}$, com profundidade de plantio de um terço do tamanho da estaca, e acondicionadas em casa de vegetação de vidro com temperatura controlada entre 20 e $25^{\circ} \mathrm{C}$, e irrigadas por aspersão três vezes ao dia.

O delineamento experimental utilizado foi o inteiramente casualizado, com três repetições, sendo cada repetição composta de 6 estacas.

Na primeira data de coleta dos ramos, o ensaio consistiu em um esquema fatorial $3 \times 5$, sendo três genótipos (Powder Blue, Delite e seleção 19), e cinco avaliações, sendo: 0; 30; 60; 90 e 120 dias após o plantio das estacas.

$\mathrm{Na}$ segunda data de coleta, seguiu-se um esquema fatorial $3 \times 4$, sendo três genótipos (Powder Blue, Delite e seleção 19), com quatro avaliações, sendo:0; 30; 60 e 90 dias após o plantio das estacas.

$\mathrm{Na}$ terceira e quarta datas de coleta dos ramos, o ensaio consistiu em um esquema fatorial $3 \times 3$, sendo três genótipos (Powder Blue, Delite e Seleção 19), com três avaliações, sendo: 0;38 e 68 dias após o enraizamento e 0;23 e 53 dias após o plantio das estacas, respectivamente. A diferença quanto ao número de dias e de avaliações entre as épocas em que as estacas foram avaliadas, está relacionada com o início da brotação e enraizamento das mesmas. As variáveis avaliadas foram o teor de amido e açúcares solúveis totais.

Os dados obtidos nos dois experimentos foram submetidos à análise de variância, pelo teste $\mathrm{F}$,e, quando significativos, foi realizada a comparação de médias pelo teste de Tukey, ao nível de 5\% de significância, utilizando o software SAS (SAS INSTITUTE, 2009).

\section{RESULTADOS E DISCUSSÃO}

Observaram-se variações significativas nos teores de amido e de açúcares solúveis totais entre as cultivares e as épocas de coletas (Tabela 1), apresentando interação significativa entre esses fatores.

A cultivar Powder Blue apresentou maiores teores de amido nos ramos das plantas-matrizes nas quatro épocas de avaliação, em relação às demais cultivares (Tabela 1). Resposta similar foi observada para os açúcares solúveis totais na primeira época de coleta dos ramos, sendo que, na segunda época, os maiores valores foram observados na cultivar Powder Blue, enquanto Delite apresentou maiores valores para esta variável na terceira e quarta épocas. Na quarta época de coleta dos ramos, pôde ser verificada queda nos teores de açúcares e aumento no teor de amido, em relação à terceira época (Tabela 1).

Nas plantas-matrizes das cvs Powder Blue e Delite, já havia ocorrido a senescência foliar na segunda época de coleta dos ramos, quando se verificou aumento no teor de amido, em relação à primeira época de coleta nos ramos da cv Powder Blue, e um aumento no teor de amido e açúcares na cv Delite (Tabela 1), em relação à primeira época de coleta (plantas possuíam folhas). Por outro lado, na Seleção 19 , verificou-se a permanência de parte das folhas nas plantas-matrizes durante todo o período em que se realizaram as coletas, o qual pode ter contribuído para o aumento no teor de amido nos ramos deste genótipo da primeira para a segunda época de coleta, e manutenção destes teores nas avaliações seguintes.

Observou-se resposta quanto à interconversão amido-açúcares nos ramos de mirtileiro da cultivar Delite, embora com a paralisação visível do crescimento vegetativo, o teor de amido e açucares tenha aumentado na segunda época de coleta dos ramos (Tabela 1). Na terceira época de coleta, pôde 
ser verificada a interconversão, ou seja, os açúcares solúveis atingiram seus picos de concentração, e o teor de amido diminuiu nos ramos. Essa resposta não se verificou no metabolismo de carboidratos da Seleção 19, possivelmente associada à oscilação térmica durante o período (Figura 2), que proporcionou ao genótipo acumular reservas na forma de amido mesmo durante o período de inverno, devido à presença de folhas.

O maior conteúdo de amido verificado na cultivar Powder Blue, possivelmente esteja relacionado ao fato de essa cultivar estar mais bem adaptada á região, sendo mais resistente a doenças, com plantas vigorosas, além de ser o genótipo de maior produtividade (SANTOS; RASEIRA, 2006).Essas condições favorecem o maior acúmulo das reservas amiláceas, essenciais para enfrentar o período de dormência e retomada do novo ciclo vegetativo.

Os maiores teores de açúcares solúveis totais observados na cv. Delite, na terceira época de coleta (Tabela 1), podem estar relacionados ao fato de esta cultivar ser mais sensível ao fotoperíodo, temperatura e o metabolismo associado à entrada em dormência, que ocorre mais precocemente em relação às demais cultivares. Na primeira época de coleta, todas as cultivares apresentavam folhas, porém a cv. Delite apresentava ramos e folhas com coloração completamente avermelhadas, ou seja, com os sinais visíveis de folhas apresentando reduzido teor de clorofilas, o que, segundo Taiz e Zeiger (2009), é um sinal de início da senescência das folhas.

A maior disponibilização de açúcares solúveis no período que se seguiu à primeira coleta de ramos (Tabela 1) observada nas cvs Seleção 19 e Delite é esperada em plantas lenhosas de clima temperado, como resposta à degradação do amido e preparo para suportar períodos de temperaturas mais baixas. Esse fato ocorre no período de dormência quando os tecidos meristemáticos das gemas apresentam baixa capacidade mobilizadora de açúcares solúveis, acompanhado de aumento da hidrólise do amido, sob baixas temperaturas, pela ação da enzima $\alpha$-amilase (WEGRZYN et al., 2000), e síntese de sacarose através da sacarose fosfato sintase - SPS - (SCHRADER; SAUTER, 2002), como forma de proteção desses órgãos ao frio.

$\mathrm{O}$ aumento no teor de amido na cultivar Powder Blue, e de amido e açúcares nas cultivares Seleção 19 e Delite, verificado na segunda época de coleta dos ramos, em relação à primeira época de coleta, pode, segundo Taiz e Zeiger (2009), estar associado à senescência das folhas, sendo que, neste período, a planta recupera parte da energia investida na formação foliar, por meio da ação de enzimas hidrolíticas que decompõem proteínas celulares (principalmente clorofilas), carboidratos e ácidos nucleicos presentes nas células das folhas. Conforme Dangl et al. (2000), durante a senescência foliar, a clorofila é convertida a clorofilídeo, em uma reação catalisada pela clorofilase, originando como subproduto o fitol, que se acumula nos lipídeos. Segundo os autores, há evidências de que a via lipídeos-açúcares é ativada durante a senescência das folhas, malato, oxaloacetato e piruvato que são prontamente interconvertidos e representam pontos de entrada de carbono na via glicolítica e/ou via dos ácidos tricarboxílicos, podendo ser utilizados tanto no processo respiratório, quanto para síntese de sacarose e/ou amido, dependendo das necessidades fisiológicas da planta.

A redução dos açúcares solúveis totais, registrada na quarta época de coleta de ramos (1108-2008), coincide com a elevação da temperatura, consequentemente, com provável aumento da taxa respiratória e da mobilização destas substâncias para as gemas, que, no referido período, já se encontravam em início de brotação. Nesse período, as gemas tornam-se fortes drenos metabólicos devido à necessidade de fornecimento de energia para suportar a brotação até as primeiras folhas iniciarem a produção de fotoassimilados.

Durante o estágio da dormência, aumenta a atividade das enzimas que degradam amido, convertendo este carboidrato de reserva em açúcares solúveis (WEGRZYN et al., 2000; SCHRADER; SAUTER, 2002). Entretanto, no presente trabalho, não se verificou uma resposta clara desta conversão de substâncias de reserva para as cultivares Powder Blue e Delite, uma vez que se registrou uma variação inconstante na concentração de amido, ao longo das épocas de avaliação, podendo estar relacionado às variações de temperatura do inverno do Sul do Brasil (Figura 1), e/ou a problemas de adaptação destas cultivares às condições climáticas onde estão sendo cultivadas.

Para a Seleção 19, embora tenha ocorrido uma redução significativa dos açúcares solúveis, a partir da segunda época de avaliação, observou-se manutenção no teor de amido, possivelmente pelo fato de este genótipo manter grande maioria das folhas, durante todo o período de avaliação, sugerindo que se trata de um genótipo com menor sensibilidade às variações de fotoperíodo/temperatura ou com alta exigência em frio para entrar em dormência, que nesse caso não ocorreu, uma vez que,no ano de 2008, o número de horas de frio registrado na estação experimental da Embrapa Clima Temperado foi de apenas 276 horas. Sendo assim, mesmo havendo demanda por açúcares para passar pelo período de baixas temperaturas, as plantas mantiveram a capacidade de produzir carboi- 
dratos para a manutenção do metabolismo da planta e para armazenar na forma de amido.

Embora o teor de açúcares solúveis tenha aumentado em ramos da Seleção 19, durante o período em que se procedeu às coletas, até a segunda época de coleta de ramos, esse aumento não foi acompanhado pela redução no teor de amido, contrariando os resultados obtidos por Bonhomme et al. (2005) em pessegueiro e por Marafon et al. (2011) em pereira, os quais observaram um estreito paralelismo entre a hidrólise do amido e o aumento no teor de açúcares solúveis totais nos ramos, durante o inverno.

$\mathrm{O}$ aumento dos açúcares sem consumo de amido na Seleção 19, possivelmente, seja uma característica do genótipo, que continuou armazenando fotoassimilados, devido à manutenção de parte do aparato foliar durante o período de inverno.

Em relação ao comportamento das estacas submetidas ao enraizamento, observou-se que o teor de amido e de açúcares solúveis variou significativamente entre cultivares e entre as épocas de coleta dos ramos (Tabela 1 ).

Na primeira data de coleta dos ramos (03-062008), a cultivar Powder Blue apresentou o maior teor de amido em relação às demais cultivares (Figura 1A); porém, após as estacas serem submetidas ao processo de enraizamento, registrou-se uma redução gradual, apresentando diferença significativa após 60 dias. A redução no teor de amido não foi acompanhada pelo aumento gradual no teor de açúcares solúveis, possivelmente pelo fato de as estacas estarem em condição de temperatura $\left(20\right.$ a $\left.25^{\circ} \mathrm{C}\right)$, que proporcionou o início da brotação (Tabela 2).

Por sua vez, a cv Delite apresentou aumento no teor de amido até os 60 dias, e este aumento foi acompanhado pelo consumo de açúcares nestas avaliações.

Nas estacas da Seleção 19, verificou-se queda significativa nos teores de amido e de açúcares aos 60 dias. Nesta avaliação, 25\% das estacas estavam com brotos (Tabela 2).

Nesta primeira época de coleta, verificou-se formação de número significativo de brotações aos 90 dias, mais tardia se comparada com as demais épocas, em que brotaram nos primeiros trinta dias.

Na segunda data de coleta (04-07-2008), os ramos de todas as cultivares apresentaram maior teor de açúcares em relação à primeira época de coleta (Tabela 1). Quando as estacas das plantas das cvs Powder Blue e Delite foram submetidas ao enraizamento, pôde-se observar que ocorreu manutenção nos teores de amido durante os primeiros 30 dias (Figura 1B), período em que se verificou redução no teor de açúcares acompanhado da emissão de brotações em
$83 \%$ das estacas de ambas as cultivares. Para a Seleção 19, verificou-se teor de amido significativamente superior aos 30 dias, acompanhado de consumo de açúcares.

Na terceira época de coleta (24-07-2008), observou-se que o teor de amido e açúcares solúveis variou consideravelmente (Figura 1C). Aos 38 dias, registraram-se valores significativamente inferiores à primeira época de avaliação para as variáveis, amido e açúcares, além da emissão de brotações nas estacas das cvs Delite e Powder Blue, na ordem de 25 e $50 \%$, respectivamente, e em $25 \%$ das estacas da Seleção 19 (Tabela 2).

Na última coleta dos ramos de mirtileiro para o enraizamento (11-08-2008), observou-se consumo significativo de amido e açúcares aos 23 dias, nos três genótipos (Figura 1D), utilizados possivelmente para a emissão de brotos, que foi na ordem de 50\% para a Seleção 19 e 33\% para as demais cultivares. Aos 53 dias, observou-se acréscimo nos teores de amido e açúcares na cv Delite, sendo que, nesta avaliação, $75 \%$ das estacas haviam emitido brotações e, possivelmente, já estavam produzindo excedentes de fotoassimilados, que estavam sendo utilizados na síntese de amido e para suportar o início da formação de raízes, pois, na avaliação realizada ao final do experimento, $100 \%$ das estacas desse ensaio estavam brotadas e mais de $80 \%$ delas apresentavam raízes (Tabela 2).

De maneira geral, pode ser verificado que estacas que apresentam ressíntese de amido são oriundas de ramos que possuem baixo teor deste carboidrato. Essa ressíntese não foi verificada na cultivar Powder Blue em nenhuma das épocas; no entanto, na cultivar Delite, ocorreu na primeira época de coleta (Figura 1A), e na Seleção 19 na segunda e terceira épocas de coleta (Figuras 1B e 1C, respectivamente). Nessas épocas de coleta, esses genótipos encontravam-se com baixo teor de amido nos ramos (Tabela 1). No entanto, quando submetidas ao processo de enraizamento, apresentaram aumento no teor de amido, acompanhado de diminuição no teor de açúcares. Essa interconversão amido-açúcares, possivelmente, seja uma "reconstituição" do grânulo de amido, visto que, de modo geral, nessas épocas de coleta, os genótipos apresentavam altos teores de açúcares solúveis no lenho, e com temperaturas da casa de vegetação mais elevadas, não houve a necessidade de manutenção dos altos níveis de açúcares para suportar o período de frio, fazendo com que as células convertessem esses açúcares em amido (PREISS; SIVAK, 1996).

A demora em emitir brotações, verificada na primeira época de coleta dos ramos, parece estar intimamente ligada ao fato de as plantas-matrizes 
estarem preparando-se para entrar no período de inverno, com o conteúdo de auxinas e de cofatores endógenos que promovem o crescimento em baixas concentrações (TSIPOURIDIS et al., 2006). Os mesmos autores verificaram, em seus estudos com o balanço de carboidratos correlacionados com a rizogênese em pessegueiros, que as maiores taxas de crescimento das brotações aconteciam nas épocas de teores mais elevados de açúcares solúveis, porém o percentual de enraizamento nestas épocas era baixo.

De modo geral, pode ser verificado que ocorre um consumo de amido e açúcares durante o processo de enraizamento. Esses resultados estão em conformidade com vários autores, que afirmam que, para o desenvolvimento de novas células vegetais,
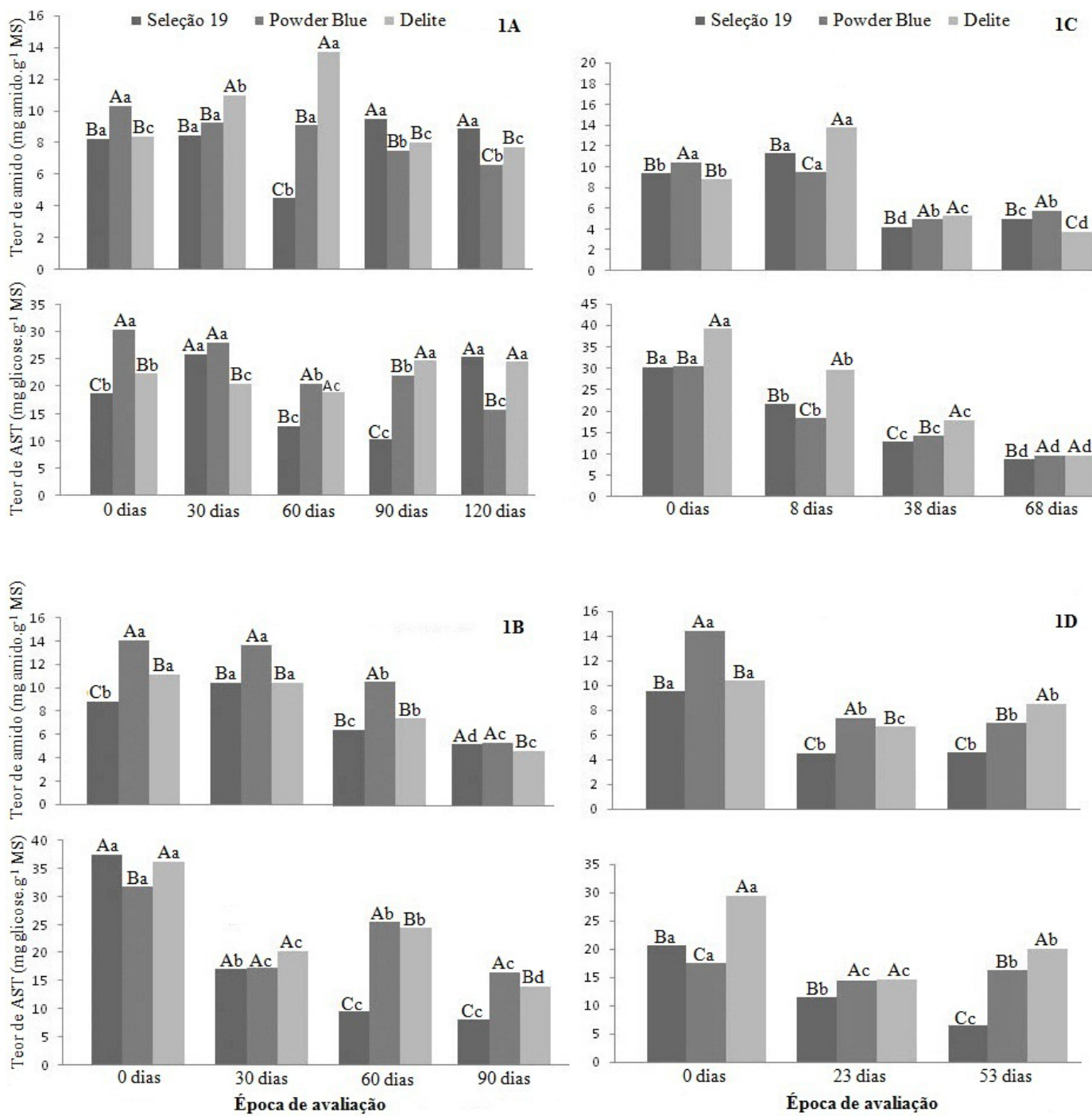

FIGURA 1 - Variação do teor de amido e açúcares solúveis totais (AST) em estacas lenhosas de mirtileiro cultivares Delite, Powder Blue e Seleção 19, submetidas ao processo de enraizamento em 03-06-2008 (1A), 04-07-2008 (1B), 24-07-2008 (1C) e 11-08-2008 (1D). CPACT/Embrapa, Pelotas-RS, 2012.

*Médias seguidas de mesma letra maiúscula na época de avaliação e médias seguidas de mesma letra minúscula entre épocas de avaliação não diferem significativamente entre si, pelo teste Tukey, a 5\% de probabilidade de erro. 
TABELA 1- Teores de amido e de açúcares solúveis totais em ramos lenhosos de mirtileiro cultivares Delite, Powder Blue e Seleção 19, em quatro épocas de coleta. CPACT/Embrapa, Pelotas-RS, 2012.

\begin{tabular}{|c|c|c|c|}
\hline \multicolumn{4}{|c|}{ Amido (mg amido $\left.\mathrm{g}^{-1} \mathrm{MS}\right)$} \\
\hline Data de coleta & Seleção 19 & Powder Blue & Delite \\
\hline 03-06 & $8,25 \mathrm{Bb}$ & $10,31 \mathrm{Ab}$ & $8,36 \mathrm{Bc}$ \\
\hline 04-07 & $8,82 \mathrm{Ca}$ & $14,12 \mathrm{Aa}$ & $11,14 \mathrm{Ba}$ \\
\hline 24-07 & $9,36 \mathrm{Ba}$ & $10,33 \mathrm{Ab}$ & $8,84 \mathrm{Bc}$ \\
\hline 11-08 & $9,48 \mathrm{Ca}$ & $14,35 \mathrm{Aa}$ & $10,34 \mathrm{Bb}$ \\
\hline$\overline{\mathrm{CV}}(\%)$ & & 6,134 & \\
\hline Média Geral & & 8,7378 & \\
\hline \multicolumn{4}{|c|}{$\begin{array}{c}\left.\text { Açucares Solúveis Totais (mg glicose } \mathrm{g}^{-1} \mathrm{MS}\right) \\
\end{array}$} \\
\hline Data de coleta & Seleção 19 & Powder Blue & Delite \\
\hline 03-06 & $18,82 \mathrm{Cd}$ & $30,52 \mathrm{Aa}$ & $22,70 \mathrm{Bd}$ \\
\hline 04-07 & $37,47 \mathrm{Aa}$ & $31,87 \mathrm{Ba}$ & $36,21 \mathrm{Ab}$ \\
\hline 24-07 & $30,26 \mathrm{Bb}$ & $30,54 \mathrm{Ba}$ & $39,23 \mathrm{Aa}$ \\
\hline 11-08 & $20,63 \mathrm{Bc}$ & $17,54 \mathrm{Cb}$ & $29,35 \mathrm{Ac}$ \\
\hline$\overline{\mathrm{CV}}(\%)$ & & 3,486 & \\
\hline Média Geral & & 21,441 & \\
\hline
\end{tabular}

*Letras diferentes, maiúsculas na horizontal e minúsculas na vertical, diferem entre si ao nível de 5\% pelo teste de Tukey.

TABELA 2- Porcentagem de enraizamento, presença de calos e de brotos em estacas lenhosas de mirtilo das cultivares Delite e Powder Blue e da Seleção 19, submetidas ao processo de enraizamento, em quatro épocas de coleta de ramos. CPACT/Embrapa, Pelotas-RS, 2012.

\begin{tabular}{|c|c|c|c|c|c|c|c|c|c|c|c|c|}
\hline \multirow{3}{*}{$\begin{array}{c}\text { Época de } \\
\text { Coleta }\end{array}$} & \multirow{3}{*}{ Cultivar } & \multirow{3}{*}{$\begin{array}{c}\text { Julho } \\
\frac{30 \text { dias }}{\text { PEB }}\end{array}$} & \multirow{3}{*}{$\frac{\text { Agosto }}{\frac{60 \text { dias }}{\text { PEB }}}$} & \multirow{2}{*}{\multicolumn{2}{|c|}{$\begin{array}{c}\text { Setembro } \\
90 \text { dias } \\
\end{array}$}} & \multirow{2}{*}{\multicolumn{2}{|c|}{$\begin{array}{l}\text { Outubro } \\
120 \text { dias } \\
\end{array}$}} & \multirow{2}{*}{\multicolumn{2}{|c|}{$\begin{array}{c}\text { Novembro/2008 } \\
150 \text { dias } \\
\end{array}$}} & \multirow{2}{*}{\multicolumn{3}{|c|}{$\begin{array}{c}\text { Janeiro/2009 } \\
235 \text { dias }\end{array}$}} \\
\hline & & & & & & & & & & & & \\
\hline & & & & PEC & PEB & PEC & PEB & PEC & PEB & PEC & PEE & PEB \\
\hline \multirow{6}{*}{$\begin{array}{c}1^{\mathrm{a}} \\
\text { época }\end{array}$} & Sel.19 & 8 & 25 & - & 58 & - & 66 & $\mathrm{nc}$ & $\mathrm{nc}$ & $\mathrm{nc}$ & $\mathrm{nc}$ & $\mathrm{nc}$ \\
\hline & P.B. & - & 8 & 16 & 41 & 33 & 41 & - & 50 & 6 & 88 & 88 \\
\hline & Delite & - & 16 & 16 & 33 & 33 & 58 & - & 16 & $\mathrm{nc}$ & $\mathrm{nc}$ & nc \\
\hline & & & 30 dias & \multicolumn{2}{|c|}{60 dias } & \multicolumn{2}{|c|}{90 dias } & \multicolumn{2}{|c|}{120 dias } & \multicolumn{3}{|c|}{208 dias } \\
\hline & Cultivar & & PEB & PEC & PEB & PEC & PEB & PEC & PEB & PEC & PEE & PEB \\
\hline & Sel.19 & - & 75 & - & 100 & - & 100 & - & $\mathrm{nc}$ & $\mathrm{nc}$ & $\mathrm{nc}$ & $\mathrm{nc}$ \\
\hline \multirow[t]{5}{*}{$2^{\mathrm{a}}$ época } & P.B. & - & 83 & - & 100 & - & 100 & - & 100 & nc & $\mathrm{nc}$ & $\mathrm{nc}$ \\
\hline & Delite & - & 83 & - & 100 & - & 100 & - & 100 & $\mathrm{nc}$ & $\mathrm{nc}$ & $\mathrm{nc}$ \\
\hline & & & 8 dias & \multicolumn{2}{|c|}{38 dias } & \multicolumn{2}{|c|}{68 dias } & \multicolumn{2}{|c|}{98 dias } & \multicolumn{3}{|c|}{186 dias } \\
\hline & Cultivar & & PEB & PEC & PEB & PEC & PEB & PEC & PEB & PEC & PEE & PEB \\
\hline & $\overline{\text { Sel.19 }}$ & - & 25 & - & 33 & 16 & 83 & - & - & 41 & - & 91 \\
\hline \multirow[t]{5}{*}{$3^{\mathrm{a}}$ época } & P.B. & - & 8 & - & 50 & - & 66 & - & - & 12 & 88 & 100 \\
\hline & Delite & - & 25 & - & 25 & 50 & 91 & - & - & $\mathrm{nc}$ & $\mathrm{nc}$ & $\mathrm{nc}$ \\
\hline & & & & \multicolumn{2}{|c|}{23 dias } & \multicolumn{2}{|c|}{53 dias } & \multicolumn{2}{|c|}{83 dias } & \multicolumn{3}{|c|}{171 dias } \\
\hline & Cultivar & & & PEC & PEB & PEC & PEB & PEC & PEB & PEC & PEE & PEB \\
\hline & $\overline{\text { Sel.19 }}$ & - & - & - & 50 & - & 66 & - & - & - & - & - \\
\hline \multirow[t]{2}{*}{$4^{\mathrm{a}}$ época } & P.B. & - & - & - & 33 & - & 75 & - & - & - & 83 & 100 \\
\hline & Delite & - & - & - & 33 & - & 75 & - & - & - & 100 & 100 \\
\hline
\end{tabular}

$* \mathrm{PEB}=\%$ de estacas brotadas $\mathrm{PEC}=\%$ de estacas com calo $; \mathrm{PEE}=\%$ de estacas enraizadas; $* *$ NC $=$ Não consta. 


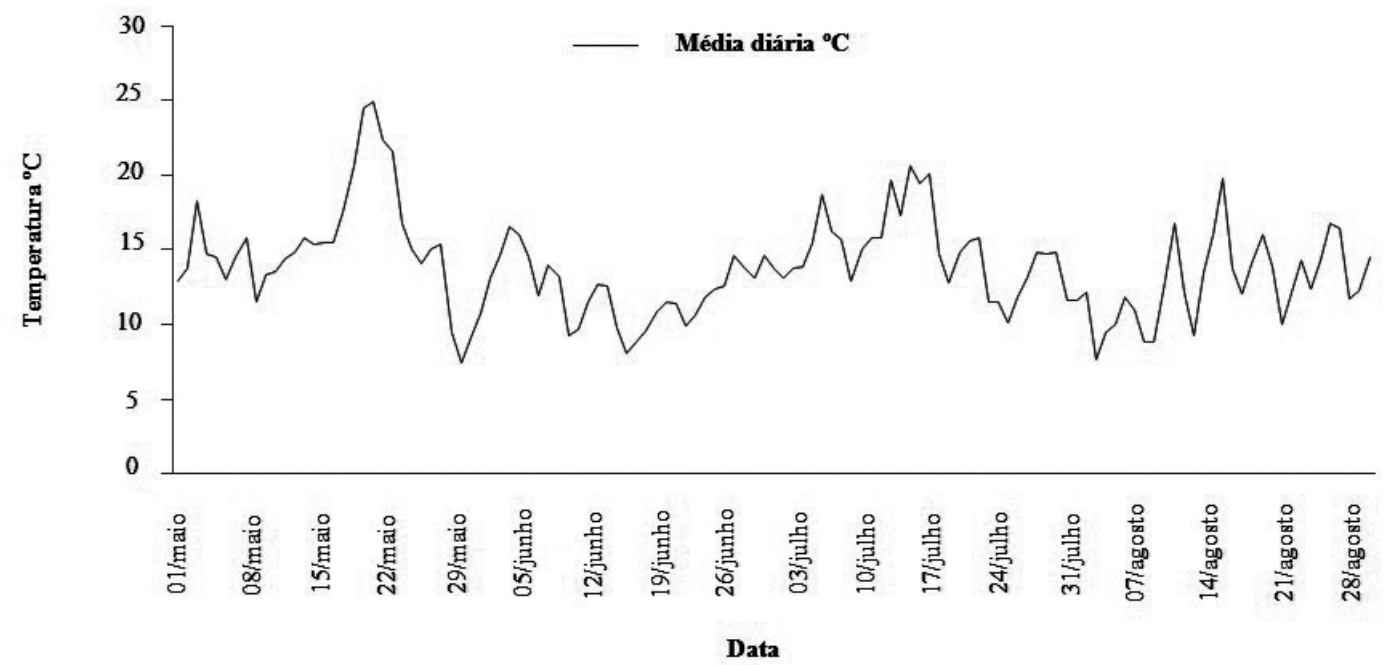

FIGURA 2 - Temperaturas médias diárias $\left({ }^{\circ} \mathrm{C}\right)$ na estação experimental do CPACT/Embrapa, durante o período de coleta dos ramos. Embrapa Clima Temperado, Pelotas-RS, 2012.

\section{CONCLUSÕES}

1. A cv. Powder Blue possui maior reserva amilácea que a cv. Delite e Seleção 19.

2. Estacas lenhosas de mirtileiro com baixos teores de amido, quando submetidas ao enraizamento, apresentam ressíntese desse carboidrato, associado à redução de açúcares solúveis totais.

3. No final do período de inverno, ocorre aumento na concentração de amido nos ramos lenhosos de mirtileiro, acompanhado de uma redução nos teores de açúcares solúveis totais.

4. Maiores teores de amido nos ramos, durante o período de inverno, estão associados à maior taxa de enraizamento das estacas lenhosas.

\section{REFERÊNCIAS}

DAVIS, T.D.; POTTER, J.R. Current photosynthate as a limiting factor in adventitious root formation on leafy pea cuttings. Journal American Society for Horticultural Science, Alexandria, v.106, p.278282, 1981.

BONHOMME, M.; RAGEAU, R.; GENDRAUD, M.; LACOINTE, A. Influences of cold deprivation during dormancy on carbohydrate contents of vegetative and floral primordia and nearby structures of peach buds (Prunus persica L. Batch) Scientia Horticulturae, Amsterdam, v.105, p.223-240, 2005. DANGL, J.F.; DIETRICH, R.A.; THOMAS, H. Senes- cence and programmed cell death. In: BUCHANAN, B.; GRUISSEM, W.; JONES, R. Biochemistry \& molecular biology of plants. Rockville,: American Society of Plant Physiologists, 2000. p. 1044-1100.

GUPTA, A. K.; KAUR, N. Sugar signaling and gene expression in relation to carbohydrate metabolism under abiotic stresses in plants. Journal of Biosciences, Kamataka, v.30, p.761-776, 2005.

GUY, C.; KAPLAN, F.; KOPKA, J.; SELBIG, J. HINCHA, D.K. Metabolomics of temperature stress - A Review. Physiologia Plantarum, Copenhagen, v.132, p.220-235, 2008.

HORWITZ, W. Official methods of analysis of the Association of Official Analytical Chemists. 12 ed. Washington: Analytical Chemistry, 1975. 1094p.

KLOTKE, J.; KOPKA, J.; GATZKE, N.; HEYER, A. G. Impact of soluble sugar concentrations on the acquisition of freezing tolerance in accessions of Arabidopsis thaliana with contrasting cold adaptation - evidence for a role of raffinose in cold acclimation. Plant Cell and Environment, Oxford, n.27: 1395-1404, 2004

LACOINTE, A.; KAJJI, A.; DAUDET, F. A.; ARCHER, P.; FROSSARD, J. S. Mobilization of carbon reserves in young walnut trees. Acta Botanica Gallica, Chatenay, v.140, n.4, p.435-441, 1993. 
LJUNG, K.; BHALERAO, R. P.; SANDBERG, G. Sites and homeostatic control of auxin biosynthesis in Arabidopsis during vegetative growth. Plant Journal, Oxford, v.29, n.4, p.465-474, 2002.

MARAFON, A. C.; HERTER, F. G.; CITADIN, I.; AMARANTE, L.; HAWERROTH, F. J. Chilling privation during dormancy period and carbohydrate mobilization in Japanese pear trees. Scientia Agrícola, Piracicaba, v.68; n.4, p. 462-468, 2011.

MAUREL, K.; LEITE, G.B.; BONHOMME, M.; GUILLIOT, A.; RAGEAU, R.; PÉTEL, G.; SAKR, S. Trophic control of bud break in peach (Prunus persica) trees: a possible role of hexoses. Tree Physiology, Victoria, n.24, p.579-588, 2004.

PREISS, J.; SIVAK, M.N. Starch synthesis in sink and sources In: ZAMSKI, E.; SCHAFFER, A.A. (Ed.). Photoassimilate distribution in plants and crops: source-sink relationships. New York: Marcel Dekker, 1996. p.63-93.

SANTOS, A.M.; RASEIRA, M.C.B. Cultivo do mirtilo (Vaccinium spp). Pelotas: Embrapa Clima Temperado, 2006. 102 p. (Sistemas de Produção, 8). SAS Institute. SAS/STAT ${ }^{\circledR}$ 9.2 USER'S GUIDE. $2^{\text {nd }}$ ed. Cary, 2009. 7869p.
SCHRADER; S.; SAUTER J.J. Seasonal changes of sucrose-phosphate synthase and sucrose synthase activities in poplar wood (Populus $x$ Canadensis Moench "robusta") and their possible role in carbohydrate metabolism. Journal of Plant Physiology, Stuttgart, v.159, p.833-843, 2002.

TAIZ, L.; ZEIGER, E. Fisiologia vegetal. 4.ed. Porto Alegre: Artmed, 2009. 719p.

TSIPOURIDIS, C.; THOMIDIS, T.; S. BLADENOPOULOU, S. Rhizogenesis of GF677, Early Crest, May Crest and Arm King stem cuttings during the year in relation to carbohydrate and natural hormone content. Scientia Horticulturae, Amsterdam, n. 108, p.200-204, 2006.

WEGRZYN, T.; REILLY, K.; CIPRIANI, G.; MURPHY, P.; NEWCOMB, R.; GARDNER, R.; MACRAE, E. A novel $\alpha$-amylase gene is transiently upregulated during low temperature exposure in apple fruit. European Journal of Biochemistry, Berlin, v.267, p.1313-1322, 2000. 